\title{
Sex preference and contraceptive behaviour among men in Mbeya region, Tanzania
}

\author{
Eleuther A Mwageni, BA (Ed), MA, PhD, Lecturer, Development Studies Institute, Sokoine University of Agriculture, Morogoro, \\ Tanzania \\ Augustine Ankomah, BA, MSc, PhD, Senior Lecturer, School of Health, University of Teesside, Middlesborough, TS1 3BA, UK \\ Richard A Powell, BA, MA, MSc, formerly Research Fellow, School of Postgraduate Medicine and Health Sciences, University \\ of Exeter, Exeter, UK.
}

Correspondence. Augustine Ankomah, Senior Lecturer, School of Health, University of Teeside, Middlesborough, TS1 3BA, UK. Tel: 01642 342769,email: A.Ankomah@tees.ac.uk

(Accepted July $31^{\text {st }}, 2000$ )

\begin{abstract}
Summary
While recent studies confirm parental child sex preference in less developed countries, its pattern varies. Son preference is especially prevalent in Bangladesh, China, India, and Pakistan. Sex preference in sub-Saharan Africa is a neglected area of enquiry. Completed research focuses on women's views to the neglect of men, despite the latter's importance as primary decision-makers.

This study identifies factors influencing contraceptive behaviour among men in Mbeya region, Tanzania, demonstrating how it is affected by their preferred family sex composition. Data used were collected from a crosssectional survey of 600 men aged 16-50 and six focus groups conducted in the region's rural and urban areas.

Using single statements and Coombs' Scales, sex preference was found to be prevalent in the study area, with sons strongly preferred to daughters. Sex preference is significantly associated with the number of existing daughters a man has, his marital status, residence and occupation.

Findings suggest programmes should be initiated to challenge men's attitudes towards one-sex family composition. Men should be educated about the advantages of small family sizes and persuaded that both children's sexes are equally important. Such measures can assist men in reconsidering their desired family sizes, reduce biases towards one sex, minimise marital problems and improve women's status. Efforts to increase contraceptive use in Tanzania will be hampered, however, if men maintain their preference for sons over daughters.
\end{abstract}

\section{Key words}

contraception, contraceptive behaviour, men, sex preference, Tanzania

\section{Key message points}

- Sex preference is prevalent in the study area, with sons strongly preferred to daughters.

- Sex preference is significantly associated with the number of existing daughters a man has, his marital status, residence and occupation.

- Programmes should challenge men's attitudes towards one-sex family composition.

- Men should be educated about the advantages of small family sizes.

- Efforts to increase contraceptive use in Tanzania will be hampered if men maintain their preference for sons over daughters.

\section{Introduction}

While recent studies confirm parental child sex preference in less developed countries, ${ }^{1-4}$ its pattern varies. Son preference is especially prevalent in Bangladesh, China, India, and Pakistan. ${ }^{5-8}$ In countries with matrilineal cultures, daughters are preferred to sons ${ }^{9-11}$; in Sri Lanka, South America, and parts of the Caribbean, parental sex preference is gender-neutral. ${ }^{1,12}$

Motivations underpinning parental child sex preference include abeyance of traditional cultural beliefs and social customs, and potential economic utility. Sons are often preferred for family labour, for the income they can earn, the financial security they can provide elderly parents, their continuance of family lineages, or to follow religious teachings (e.g. for Hindus, sons kindle the funeral pyre of deceased parents). ${ }^{13}$ Daughters importantly perform familial duties or household chores. ${ }^{14-17}$

It is contended that son preference partly explains low contraceptive use and high total fertility rates (TFRs) in less developed countries. Desire for sons affects preferred family size, in turn influencing contraceptive use. Couples continue bearing children despite attaining their desired family size because they are dissatisfied with their offspring's sex; there is a need for additional sons. The relationship between son preference and reproductive behaviour in less developed countries is, however, ambiguous. For example, in a comparative study of India, Morocco and Pakistan, Repetto ${ }^{18}$ reported a positive correlation: families with a high proportion of sons had higher fertility levels than those without sons or those with more daughters. Similar findings were reported in China and Sri Lanka. ${ }^{19,2}$

When the desire for sons is satisfied, however, fertility preferences and contraceptive behaviour change. Parents with more sons than daughters are less likely to desire additional children. Das reported that contraceptive use among Indian couples rose with an increase in the number of existing sons, the exception being couples with only sons. ${ }^{20}$ Using data gathered from industrial workers in two of Pakistan's largest cities, Farooqui found that contraceptive use rises with an increase in the number of sons. ${ }^{21}$ A longitudinal study conducted by Rahman et al in Matlab, Bangladesh, revealed that couples with large families but no sons were less likely than other couples to use contraceptives, ${ }^{22}$ while Chowdhury et al found a higher number of sons at each family size was associated with more women desiring no more children. ${ }^{23}$

Sex preference in sub-Saharan Africa is a neglected area of study. Existing evidence indicates that, while not universal, ${ }^{1,24}$ sons are preferred to daughters. ${ }^{14,25-27}$ This sex preference reportedly influences contraceptive behaviour. Campbell found that son preference among men in western Sierra Leone affected their fertility attitudes. ${ }^{14}$ 
Indeed, Adamchack and Adebayo's study of Nigerian male students studying in the USA found $35 \%$ of respondents thought men should either marry a second wife or continue to have children in the absence of sons. ${ }^{28}$

In sub-Saharan Africa, research into sex preference has largely focused on women's views, to the neglect of men's opinions. $^{29-32}$ In a continent where men are the primary decision-makers (both in public and domestic life) and income earners, reproductive intentions are substantially influenced by their preferences. ${ }^{33-35}$ This appears especially relevant in the initial stages of a couple's reproductive lives (i.e. associated with four or fewer children). ${ }^{36}$ Neglecting men's views of sex preference distorts the true picture of sexual and reproductive behaviour across sub-Saharan Africa. This paper consequently investigates the relationship between men's sex preferences and contraceptive behaviour.

\section{Method}

Data used in this study derive from a cross-sectional survey and focus group discussions conducted in six areas of Mbeya region, south-west Tanzania, between January and March 1994. Tanzania, which recently has witnessed a decline in its TFR, ${ }^{37-38}$ has an estimated population of 30.6 million and an annual natural population growth rate of $2.5 \%{ }^{39}$ Mbeya region is located in the southern highlands of Tanzania, approximately 600 kilometres west of the capital, Dar es Salaam.

Three wards each were selected from Mbeya's urban and rural districts (i.e. Mabatini, Ruanda and Sisimba, and Iwindi, Mapogoro and Tembela, respectively). The survey employed a multi-stage sampling technique, drawing a sample of 600 men (360 and 240 from the rural and urban districts, respectively), aged between 16 and 50 years. Stratified initially by place of residence (i.e. urban or rural), a proportional sample was derived from enumeration areas, a simple random method used to select three rural and three urban areas characterised by low, medium, and high population densities. Of these wards, two villages were selected using the same method. Households within each village were then selected, again using a simple random method. Closed and open-ended questions were used to collect information about respondents' demographic characteristics and socio-economic background, sex preferences, and contraceptive behaviour.

Additionally, the study used findings from six focus groups held to investigate in depth the attitudinal and experiential factors underpinning men's contraceptive behaviour. The focus groups (stratified by age [16-30 and 31-50] and residence [urban and rural]) were conducted in the same areas as those selected for the survey, but used different participants. ${ }^{40}$

\section{Coombs'Scales}

Analysis of sex preference used the Coombs' Scale. ${ }^{41}$ Not only has the Coombs' Scale been used in less developed countries, it has also proved more effective in predicting reproductive behaviour than single statements. ${ }^{42,16}$ The Scale provides a measure of desired familial sex composition (known as the IS scale), placing respondents on a continuum of sex preferences ranging from one (extreme girls' preference) to seven (extreme boys' preference). The complete Scale is often grouped as follows: girls' preference (IS 1-3), balanced preference (IS 4) and boys' preference (IS 5-7). Data required to locate an individual on the IS scale is obtained from a series of questions addressed to a respondent regarding their preferred family sex composition. The study additionally presents a further measure of sex preference: a single item statement of desired family sex composition.

Using the Coombs' Scale, respondents were asked four questions regarding their sex preferences for children, each question offering different scenarios. Respondents were required to choose their ideal scenario if they had an opportunity to bear only three children throughout their lifetime. A minimum odd number was used to maximise the biases of respondents' sex preferences. Using these questions, each respondent's IS scale was estimated.

\section{Results}

As Table 1 shows, men in Mbeya region have a strong preference for sons, with $87 \%$ of respondents choosing either two boys and one girl or three boys in the first scenario. In the second and third scenarios, the overwhelming majority of men chose sons (95\% and $94 \%$, respectively); respondents also indicated their preference for sons in the fourth scenario $(59 \%)$.

Despite the overwhelming preference for sons, however, it appears an absence of daughters is undesirable. This was clearly revealed when respondents were asked in the fourth scenario to choose between having either three boys only or two girls and one boy: Forty percent of men stated their preference for the latter.

Single-item statements expressing preferred sex composition, however, have their limitations: they fail to consider preferences expressed beyond the first choice. In order to circumvent this problem, further analysis was conducted using the Coombs' IS Scale. The IS scale also indicates men in Mbeya region have a preference for sons over daughters. Table 2 reveals that only $10 \%$ of men

Table 1 Preferred sex of children among men in Mbeya Region, Tanzania

\begin{tabular}{lll}
\hline Sex Composition & Responses & \\
& Per cent & Number \\
\hline
\end{tabular}

First scenario

If you could have 3 children in total which combination would you choose?

Three girls

Two girls and one boy

Two boys and one girl

Three boys

Don't know

$\begin{array}{rr}1.3 & 8 \\ 10.3 & 62 \\ 72.8 & 437 \\ 14.2 & 85 \\ 1.3 & 8 \\ 100 & 600\end{array}$

Second scenario

Suppose the only choice you could have was 2 boys and 1 girl or 3 girls. Which would you prefer?

Two boys and one girl

Three girls

Don't know

$\begin{array}{rr}95.4 & 572 \\ 3.3 & 20 \\ 1.3 & 8 \\ 100 & 600\end{array}$

Third scenario

Imagine that you have an alternative between 3 boys or 3 girls. Which would you choose?

$\begin{array}{lrr}\text { Three boys } & 94.0 & 564 \\ \text { Three girls } & 4.3 & 26 \\ \text { Don't know } & 1.7 & 10 \\ & 100 & 600\end{array}$

Fourth scenario

If you could choose only between 3 boys or 2 girls and 1 boy, which scenario would be your choice? 
prefer daughters, while $2 \%$ prefer a balanced sex composition among their children and $88 \%$ have a preference for sons.

This sex preference appears common among all respondents regardless of their age, number of living and dead children, number of sons, number of wives, residence before age 15, religion, and education. The findings suggest, however, that sex preference is associated with number of daughters, marital status, current residence, and occupation. Although there appears to be a relationship

Table 2 Percentage distribution of IS scale values by men's background characteristics

\begin{tabular}{|c|c|c|c|c|c|c|}
\hline \multirow[b]{2}{*}{ Background variable } & \multirow[b]{2}{*}{$\begin{array}{l}\text { Daughter bias - } \\
\text { IS } 1-3\end{array}$} & \multicolumn{2}{|c|}{ IS Scale values } & \multirow[b]{2}{*}{$\begin{array}{l}\text { Son bias } \\
\text { IS 6-7 }\end{array}$} & \multirow{2}{*}{\multicolumn{2}{|c|}{ Significance level }} \\
\hline & & IS 4 & IS 5 & & & \\
\hline \multicolumn{7}{|l|}{ Age } \\
\hline $16-19$ & 6.8 & 3.4 & 45.8 & 44.0 & & \\
\hline $20-24$ & 7.1 & 0.0 & 39.8 & 53.1 & & \\
\hline $25-29$ & 9.5 & 0.8 & 44.4 & 45.2 & 40.4 & .097 \\
\hline $30-34$ & 10.9 & 5.5 & 38.2 & 45.4 & & \\
\hline $35-39$ & 14.7 & 1.5 & 48.5 & 35.3 & & \\
\hline $40-44$ & 8.6 & 0.0 & 46.6 & 44.8 & & \\
\hline $45-50$ & 17.5 & 2.5 & 45.0 & 35.0 & & \\
\hline \multicolumn{7}{|l|}{ Children living } \\
\hline No children & 9.1 & 1.4 & 35.6 & 53.9 & & \\
\hline 1-3 children & 8.4 & 1.9 & 50.5 & 39.2 & 26.4 & .152 \\
\hline 4-6 children & 13.4 & 3.6 & 39.3 & 43.7 & & \\
\hline $7+$ children & 12.5 & 0.0 & 48.2 & 39.2 & & \\
\hline \multicolumn{7}{|l|}{ Dead children } \\
\hline Zero & 9.9 & 2.2 & 42.5 & 45.3 & 6.9 & .73 \\
\hline One & 13.1 & 1.3 & 42.2 & 43.4 & & \\
\hline Two+ & 6.7 & 0.0 & 46.7 & 46.7 & & \\
\hline \multicolumn{7}{|l|}{ Number of sons } \\
\hline Zero & 8.4 & 1.8 & 38.7 & 41.0 & 12.7 & .624 \\
\hline $1-3$ & 11.4 & 1.9 & 47.7 & 39.0 & & \\
\hline $4-6$ & 11.8 & 1.0 & 39.2 & 47.1 & & \\
\hline $6+$ & 0.0 & 0.0 & 0.0 & 100.0 & & \\
\hline \multicolumn{7}{|l|}{ Number of daughters } \\
\hline Zero & 8.2 & 1.8 & 37.4 & 52.6 & 28.6 & .018 \\
\hline $1-3$ & 10.1 & 2.0 & 48.6 & 39.3 & & \\
\hline $4-6$ & 19.3 & 1.7 & 43.9 & 35.1 & & \\
\hline $6+$ & 0.0 & 0.0 & 60.0 & 40.0 & & \\
\hline \multicolumn{7}{|l|}{ Marital status } \\
\hline Single & 8.9 & 2.1 & 34.2 & 60.3 & 18.5 & .05 \\
\hline Married & 10.8 & 1.8 & 45.4 & 42.0 & & \\
\hline \multicolumn{7}{|l|}{ Number of wives ${ }^{1}$} \\
\hline One & 10.3 & 1.8 & 47.0 & 40.9 & 5.6 & .84 \\
\hline Two+ & 11.8 & 2.4 & 35.3 & 51.7 & & \\
\hline \multicolumn{7}{|l|}{ Residence } \\
\hline Rural & 5.4 & 1.1 & 40.9 & 52.6 & 33.5 & .000 \\
\hline Urban & 16.8 & 2.9 & 45.8 & 34.5 & & \\
\hline \multicolumn{7}{|l|}{ Residence before 15} \\
\hline Rural & 8.2 & 1.8 & 44.1 & 45.8 & 7.4 & .19 \\
\hline Urban & 15.9 & 2.2 & 39.9 & 42.0 & & \\
\hline \multicolumn{7}{|l|}{ Religion } \\
\hline Traditional & 4.7 & 1.6 & 50.0 & 43.7 & & \\
\hline Moslem & 4.8 & 0.0 & 50.0 & 45.2 & 9.4 & .49 \\
\hline Christian & 10.2 & 2.1 & 41.2 & 45.5 & & \\
\hline \multicolumn{7}{|l|}{ Education } \\
\hline No formal & 10.6 & 2.1 & 27.7 & 59.5 & & \\
\hline Primary & 7.2 & 2.0 & 43.8 & 44.6 & 16.8 & .669 \\
\hline Secondary & 11.4 & 1.1 & 44.3 & 42.1 & & \\
\hline Higher learning & 20.0 & 0.0 & 50.0 & 30.0 & & \\
\hline \multicolumn{7}{|l|}{ Occupation } \\
\hline Low status & 6.8 & 1.4 & 43.0 & 48.8 & & \\
\hline Medium status & 14.1 & 2.8 & 42.9 & 40.1 & 25.1 & .01 \\
\hline High status & 33.3 & 0.0 & 41.7 & 25.0 & & \\
\hline $\begin{array}{l}\text { All men } \\
(\mathrm{N}=590)\end{array}$ & 10.0 & 1.9 & 42.9 & 45.2 & & \\
\hline
\end{tabular}

The number of respondents for this variable was 397. 
between residence and sex preference, with respondents from rural areas more likely to exhibit higher levels of son preference than their urban counterparts, the qualitative data revealed no such differences. Focus group participants in both rural and urban areas asserted sons are preferred to daughters in their communities, a point raised by men in both rural and urban and lower and higher age groups.

There appear to be several reasons for this son preference. Most participants argued that sons are preferred for reasons of lineage and inheritance. As the following quotations reveal, sons, unlike daughters, are expected to inherit men's wealth (as heads of households) and extend the family, as well as the clan, name:

'A son can bring grandchildren, the grandchildren will be mine for the sake of my name. A daughter is not important to me in that aspect' (rural, higher age).

'When a man has a daughter, he says "I am losing my Ukoo (clan name)". But with a son he says "I am strengthening my Ukoo"' (urban, lower age).

Traditional African social and economic organisations consider lineage and inheritance of paramount importance. In most traditional societies, property (e.g. land) was rarely individually owned. Ownership of the major means of production was held by the clan, in which male members retained and controlled the rights to use property. Through inheritance, these economic and social rights were passed to male heirs, usually first sons. These traditions and attitudes still prevail in most African societies. Accordingly, a married man who has children but no son may lack social status and feel inferior to others. As one man reported:

'I say, you have refreshed my wound [about this issue].

I have nine children and all are daughters ... I have no sons. Now I am being told, "You are still a child, you are not yet married! Even when you die your name will die also"" (rural, higher age).

Another reason voiced by men in both rural and urban older age groups for son preference concerned the burden posed by grandchildren borne to unmarried daughters. Many daughters who become mothers without stable partners continue to live with their parents. Unable to achieve economic independence, they become a financial burden. As one participant commented:

'Let me elaborate on the problems facing parents currently. Daughters get pregnant before getting married! Obviously these daughters have unstable relationships. Now, who should look after their children? Obviously the parents! Therefore, as a parent I get a very big burden! I have brought her up and yet she brings another burden to me!' (rural, higher age).

Moreover, these grandfathers felt the fathers of their grand-children could come forward at any time in the future and claim their children.

As discussed earlier, although men have a preference for sons, it appears the absence of daughters is undesirable. The preferences of men, as indicated on the Coombs' Scale, are not towards the very extreme values (i.e. between IN 6 and 7); indeed, over two-fifths $(43 \%)$ lie on the IN 5 scale value. As Table 2 indicates, there is a degree of preference for daughters, particularly among men with high status occupations (33\%). One reason for this may be an awareness among this group that both sexes are equally important, their educational and occupational status possibly enabling them to break with traditions designating one sex more valuable than the other.

Additionally, it is possible some respondents continue to receive the traditional advantages associated with having more daughters. In Tanzania daughters are valued partly for the bride-wealth paid by the groom and his family to prospective in-laws to legitimate a marriage. Traditional bride-wealth in many societies includes live animals (e.g. cattle, goats and chicken) or labour. ${ }^{43}$ Nowadays it is common practice to pay cash to supplement and/or substitute other forms of bride-wealth.

As Table 3 shows, the relationship between contraceptive behaviour and sex preference is significantly related to men's knowledge of, and ever and current use of, contraceptives. Respondents with a high IS (i.e. high preference for boys) are less likely to have ever used contraceptives in the past and, more importantly, less likely to be currently doing so.

Men in Mbeya region have a strong preference for sons, a preference inversely related to contraceptive behaviour.

\section{Discussion}

Son preference is significant in Mbeya region, Tanzania, and is largely attributable to the traditional value accorded male children for their role in inheritance and as a vehicle to extend family and clan names. The disadvantages of caring for grandchildren born to unmarried daughters is

Table 3 Percentage distribution of sex preference IS scale values by men's contraceptive behaviour

\begin{tabular}{|c|c|c|c|c|c|c|}
\hline \multirow[b]{2}{*}{ Contraceptive Behaviour } & \multirow[b]{2}{*}{$\begin{array}{l}\text { Daughter bias } \\
\text { IS } 1-3\end{array}$} & \multicolumn{2}{|c|}{ IS Scale values } & \multirow[b]{2}{*}{$\begin{array}{l}\text { Son bias } \\
\text { IS 6-7 }\end{array}$} & \multirow{2}{*}{\multicolumn{2}{|c|}{ Significance level }} \\
\hline & & IS 4 & IS 5 & & & \\
\hline \multicolumn{7}{|l|}{ Knowledge of methods } \\
\hline Yes & 9.9 & 2.3 & 41.2 & 46.8 & 12.5 & 0.006 \\
\hline No & 10.2 & 1.3 & 44.5 & 43.9 & & \\
\hline \multicolumn{7}{|l|}{ Ever-use } \\
\hline Yes & 8.8 & 0.9 & 48.0 & 42.3 & 53.6 & 0.000 \\
\hline No & 10.8 & 2.5 & 38.4 & 48.3 & & \\
\hline \multicolumn{7}{|l|}{ Current use } \\
\hline Yes & 10.7 & 1.4 & 45.7 & 42.1 & 39.3 & 0.000 \\
\hline No & 9.9 & 2.0 & 40.9 & 48.6 & & \\
\hline \multicolumn{7}{|l|}{ Intention to use } \\
\hline Yes & 9.7 & 1.6 & 41.2 & 47.6 & 9.5 & 0.145 \\
\hline No & 10.3 & 2.6 & 51.8 & 35.3 & & \\
\hline \multicolumn{7}{|l|}{$\begin{array}{l}\text { All men } \\
(\mathrm{N}=600)\end{array}$} \\
\hline & 10.0 & 1.9 & 42.9 & 45.2 & & \\
\hline
\end{tabular}


another reason for son preference. Sex preference is more likely to be associated with a man's number of existing daughters, marital status, residence, and occupation. Evidence suggests, however, that a total absence of daughters is undesirable; no evidence exists suggesting a significant preference for a balanced offspring composition.

The study also showed an association between sex preference and contraceptive behaviour. Sex preference among men is significantly inversely related with ever and current use of contraceptives: men with a strong son preference are less likely to use contraceptives than are their counterparts.

These findings suggest that programmes should be initiated to challenge men's attitudes towards one-sex family composition. Son preference among men may have a negative impact upon women's social development; in societies where son preference is strong, women's status is generally low. In such societies, women's security and status may depend upon producing sons; the more sons she produces, the higher her security and status among her inlaws and her community.

Daughters may also be affected psychologically, left feeling they are unwanted. Their social status is liable to be affected, too: society is more likely to favour sons' than daughters' welfare. This can be seen in terms of educational and occupational advancement: more opportunities are likely to be offered to sons than daughters. This fact partly explains why lower proportions of women than men are found in educational institutions, high status occupations, and top managerial and administrative positions in Tanzania. Such conditions may not only affect women's decision-making potential within the immediate family and community, but also at a national level.

Since childbearing is directly a woman's concern, men's son preference may also be deleterious to women's reproductive health. Efforts to fulfil their husbands' desire for sons may require women to bear additional children. Consistent child bearing may not only affect their physiological well-being, but also increase their morbidity and mortality risk.

The study findings indicate that men should be educated about the advantages of small family sizes and persuaded that both children's sexes are equally important. Such measures can assist men in reconsidering their desired family sizes, reduce biases towards one sex, minimise marital problems and improve women's status. Efforts to increase contraceptive use in Tanzania will be hampered, however, if men maintain their preference for sons over daughters.

\section{Acknowledgements}

The lead author is grateful to the British Council for funding his studies at the Institute of Population Studies, University of Exeter, England, and to Sokoine University of Agriculture, Tanzania, for meeting his fieldwork costs.

\section{Statements on funding and competing interests}

Funding. None.

Competing interests. None.

References

F. Gender Preferences for Children. DHS Comparative Studies No.23. Calverton, Maryland: Macro International Inc., 1997.

2 DeSilva WI. Influence of son preference on the contraceptive use and fertility of Sri Lankan women. Journal of Biosocial Science 1993; 25 (3): 319-331.

Krishnan V. Gender of children and contraceptive use. Journal of Biosocial Science 1993; 25 (2): 213-221.

Pong S. Sex preference and fertility in peninsular Malaysia. Studies in Family Planning 1994; 25 (3): $137-148$.

Mothers education and effect of son preference on fertility in Matlab, Bangladesh. Population Research and Policy Review 1994; 13 (3): 257-273.

Graham MJ, Larsen U, Xu X. Son preference in Anhui Province, China. International Family Planning Perspectives 1998; 24 (2): 72-77. Scandinavian Journal of Social Medicine 1994; 22 (4): 242-248.

Socio-Cultural Ideology: a case study of two urban centres of Pakistan Framework of University of Exeter, 1994.
9 Cleland J, Verrall J, Vaessen M. Preference for the Sex of Children and their Influence on Reproductive Behaviour. World Fertility Survey Comparative Studies, Cross National Summaries No. 27. Voorburg, Netherlands: International Statistical Institute, 1983.

10 Pullum TW. Correlates of family size desire. In Bulatao RA and Lee RD (eds.) Determinants of Fertility in Developing Countries. New York: Academic Press, 1983, pp344-368

Sargent C, Harris M. Gender ideology, child-rearing and child health in Jamaica. American Ethnologist 1992; 19 (3): 523-537.

12 United Nations. Selected factors affecting fertility and fertility preferences in developing countries. World Fertility Survey Conference 1980: Record of Proceedings, Volume 2. New York: United Nations, 1982, pp.141-227.

13 Mutharayappa R., Choe MJ, Arnold F, et al. Son Preference and its Effect on Fertility in India. National Family Health Survey Subject Reports, No.3. International Institute for Populatio Sciences, Mumbai, India and East-West Centre Programme on Population, Hawaii, USA, 1997

14 Campbell EK. Sex preferences for offspring among men in the western area of Sierra Leone. Journal of Biosocial Science 1991; 23 (3): 337-342.

5 Jejeebhoy SJ, Kulkarni S. Reproductive motivation: a comparison of wives and husbands in Maharashtra, India. Studies in Family Planning 1989; 20 (5): 264-272.

16 Karki YB. Sex preference and value of sons and daughters. Studies in Family Planning 1988; 9(3): $169-178$.

17 Niraula BB, Morgan SP. Son and daughter preferences in Benighat, Nepal: implications for ertility transition. Social Biology 1995; 42 (3-4): 256-273.

8 Repetto R. Son preference and fertility behaviour in developing countries. Studies in Family Planning 1972; 3 (4): 70-76.

9 Arnold F, Zhaoxiang L. Sex preferences, fertility and family planning in China. Population (2): $221-246$

Das N. Sex preference and fertility behaviour: a study of recent Indian data. Demography 1987; 24 (4): $517-530$.

Farooqui MNI. Son preference, fertility desire and contraceptive use in two largest cities of Pakistan. Pakistan Population Review 1990; 1 (1): 54-64.

Rahman M, Akbar J, Phillips JF, et al. Contraceptive use in Matlab, Bangladesh: the role of gender preference. Studies in Family Planning 1992; 23 (4): 229-242.

23 Chowdhury AI, Bairagi R, Koening MA. Effects of family sex composition on fertility preference and behaviour in rural Bangladesh. Journal of Biosocial Science 1993; 25 (4)

24 Clark S, Colson E, Lee J, et al. 10,000 Tonga: a longitudinal anthropological study from Southern Zambia, 1956-91. Population Studies 1995; 49 (1): 91-109.

Campbell EK, Campbell PG. Family size and sex preferences and eventual fertility in Botswana. Journal of Biosocial Science 1997; 29 (2): 191-204.

26 McCarthy J, Oni GA. Desired family size and its determinants among urban Nigerian women: two-stage analysis. Demography 1987

作

Adamchak DJ, Adebayo A. Male fertility attitude: Becker S. Couples and reproduct

30 Bertrand JT, Makani B, Edwards MP, et al. The male versus female perspectives on family planning: Kinshasa, Zaire. Journal of Biosocial Science 1996; 28 (1): 37-55. Dodoo FNA. A couple analysis of micro-level supply demand factors in fertility regulation. Population Research and Policy Review 1993; 12 (2): 93-101

32 Dodoo FNA, Luo Y, Panayotova E. Do male reproductive preferences really point to a need to refocus fertility policy? Population Research and Policy Review 1997; 16 (5): 447-455. Ezeh AC. The influence of spouses over each others contraceptive attitudes in Ghana. Studies in Family Planning 1993; 24 (3): 163-174.

34 Isiogu-Abanihe UC. Reproductive motivation and family size preferences among Nigerian men. Studies in Family Planning 1994, 25 (3): 149-16

Muvandi I. Fertility behaviour and contraceptive use in Kenya: findings from a male survey. African Journal of Fertility, Sexuality and Reproductive Health 1996; 1 (2): 136-145. Bankole A. Desired fertility and fertility behaviour among the Yoruba of Nigeria: a study of couple preferences and subsequent fertility. Population Studies 1995; 49 (2): 317-328.

Mturi AJ, Hinde PRA. Recent demographic change in Tanzania: causes, consequences an future prospects. Journal of International Development 1995; 7 (1): 117-134

Population Reference Bureau. World Population Data Sheet. Washington, D.C.: Population

40 Reference Bureau, 1998 . region, Tanzania: a rural-urban comparison of qualitative data. Journal of Biosocial Science 998; 30: 381-392

41 Coombs CH, Coombs LC, McClleland GM. Preference scales for number and sex of children. Population Studies 1975; 29 (2): 273-298.

2 Coombs LC. Prospective fertility and underlying preferences: a longitudinal study in Taiwan. Molnos A Cultural Source Materials for Population in East Africa.Vol.III: beliefs and practices. Nairobi: East African Publishing House, 1973. 